\title{
Severe oedema in a patient with diabetes
}

\author{
Authors: Apichaya Amrapala ${ }^{A}$ and Tahseen A Chowdhury ${ }^{B}$
}

\begin{abstract}
A 38-year-old South Asian woman with a long-standing history of poorly controlled diabetes was admitted with severe oedema. Two weeks earlier, she had been treated with insulin for uncomplicated diabetic ketoacidosis. Renal, liver and cardiac causes of oedema were excluded, and it was assumed she may have developed 'insulin oedema'. She responded well to oral diuretics and symptoms resolved within a few weeks. Insulin oedema is an uncommon cause of oedema in patients recently commenced on insulin therapy.
\end{abstract}

KEYWORDS: Insulin, oedema, diabetes

\section{Case Presentation}

A 38-year-old South Asian woman was admitted with 1-week history of oedema that started in her legs and gradually spread to her arms and face. She stated she had gained around $14 \mathrm{~kg}$ in weight in 1 week. She complained of mild shortness of breath, but had no other symptoms of note.

She had a past history of gestational diabetes at the age of 18 years, which persisted post-delivery and was treated as type 2 diabetes. At the time, she was morbidly overweight. She had poor concordance with oral therapy and was commenced on insulin by her primary care team, but 1 year prior to admission had decided to stop insulin and manage her diabetes with a very low carbohydrate diet. During this period, she lost approximately $50 \mathrm{~kg}$ in weight. Glycaemic control, however, was extremely poor (glycated haemoglobin $\left(\mathrm{HbA}_{1 \mathrm{c}}\right) 133 \mathrm{mmol} / \mathrm{mol}(<42)$ ). There were no known complications of her diabetes.

Two weeks prior to the current admission, she was treated for uncomplicated diabetic ketoacidosis ( $\mathrm{pH} 7.145$ (7.35-7.45), plasma glucose $24.9 \mathrm{mmol} / \mathrm{L}(4-6)$, plasma ketones $6.0 \mathrm{mmol} / \mathrm{L}(<3.0)$ ) and was discharged home within 3 days on twice daily mixed insulin as she was insistent she could not manage a four times daily insulin regimen.

On examination on this admission, she was comfortable at rest. There was marked pitting oedema bilaterally to the level of her sacrum and around her arms and face. Her body mass index (BMI) was $29.6 \mathrm{~kg} / \mathrm{m}^{2}$. Respiratory rate was 20 breaths per minute, saturations $96 \%$ on room air, temperature $36.7^{\circ} \mathrm{C}$, pulse $103 \mathrm{bpm}$ regular and blood pressure $155 / 76 \mathrm{mmHg}$. Jugular venous

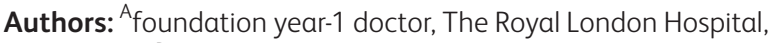
London, UK; ${ }^{B}$ consultant in diabetes, The Royal London Hospital, London, UK pressure (JVP) was not elevated. Chest was clear and heart sounds were normal. Abdominal examination was normal. Baseline investigations are shown in Table 1.

\section{What is the differential diagnosis?}

Oedema is commonly caused by renal, hepatic or cardiac disease. While serum albumin was slightly low, nephrotic syndrome was excluded with a urinalysis negative for protein. Cardiac failure was deemed clinically improbable due to the lack of chest signs and normal JVP. A further possibility was hepatic disease, including cirrhosis or Budd-Chiari syndrome, but relatively normal liver

Table 1. Baseline investigations on admission

Haemoglobin

$103 \mathrm{~g} / \mathrm{L}(115-151)$

Mean cell volume

$89.3 \mathrm{fL}(79-96)$

Platelets

$231 \times 10^{9} / \mathrm{L}(140-400)$

White cell count

$7.2 \times 10^{9} / \mathrm{L}(4-11)$

Sodium

$139 \mathrm{mmol} / \mathrm{L}(135-145)$

Potassium

$4.5 \mathrm{mmol} / \mathrm{L}(3.5-5.0)$

Urea

$4.2 \mathrm{mmol} / \mathrm{L}(2.0-6.6)$

Creatinine

$38 \mu \mathrm{mol} / \mathrm{L}(45-90)$

Bilirubin

$4 \mu \mathrm{mol} / \mathrm{L}(1-17)$

Alanine transaminase

$49 \mathrm{IU} / \mathrm{L}(0-33)$

Albumin

$33 \mathrm{~g} / \mathrm{L}(35-50)$

Total protein

$53 \mathrm{~g} / \mathrm{L}(60-80)$

International normalised ratio

1.2

C-reactive protein

$59 \mathrm{mg} / \mathrm{L}(<5)$

Cholesterol

$7.7 \mathrm{mmol} / \mathrm{L}(0-5)$

Urine pregnancy test

Urine dip

Negative

Negative

Urine protein

$<0.04 \mathrm{~g} / \mathrm{L}(<0.2 \mathrm{~g} / \mathrm{L})$

Urine microscopy, culture and sensitivity

Chest radiogram

Negative. No red cell or white cell casts detected.

Normal. No pleural effusion or pulmonary oedema.

Electrocardiogram T-wave inversion, possible left ventricular heart strain. 
function tests and ultrasound made these unlikely. Insulin oedema was considered as the oedema occurred shortly after insulin was commenced.

\section{Initial management}

The patient was started on oral furosemide $40 \mathrm{mg}$ daily and her weight, blood pressure, capillary blood glucose and routine bloods were monitored daily. Insulin doses and diabetic medications were adjusted accordingly to optimise glucose control.

\section{Case progression and outcome}

All subsequent investigations, including thyroid function, autoantibody screen and liver screen were normal. Urine protein was $<0.04 \mathrm{~g} / \mathrm{L}(<0.2 \mathrm{~g} / \mathrm{L})$ showing no evidence of proteinuria. Renal and liver ultrasound scan was normal. Echocardiogram was similarly normal, with normal left ventricular systolic function.

The patient remained clinically well, and her oedema responded well to oral furosemide, with $3 \mathrm{~kg}$ weight loss over 3 days. She was discharged with plans for follow-up, but failed to attend. Contact with her general practitioner elicited that she was symptomatically much improved, and had stopped the furosemide, but was continuing to take her insulin therapy.

\section{What is the likely diagnosis?}

After exclusion of other causes, insulin oedema was deemed the most likely diagnosis. Oedema onset was shortly after initiation of insulin therapy, the patient remained clinically well and her clinical picture did not seem to fit with any particular pattern of organ dysfunction.

\section{Discussion}

Insulin oedema is uncommon, and the extent of oedema may vary from limited ankle swelling to severe, as observed in this patient. In previously reported cases, oedema is often observed shortly after initiation or intensification of insulin treatment and occurs in both type 1 and type 2 diabetes. This case highlights the difficulty of conclusively diagnosing insulin oedema - it is a diagnosis of exclusion and there are no criteria or risk stratification systems to aid diagnosis. Poor glucose control and low BMI have been suggested as risk factors. ${ }^{1}$

Currently there are no treatment guidelines for this condition. The condition may improve with diuretic therapy. ${ }^{2}$ Other options include conservative measures such as compression stockings or salt and fluid restriction. ${ }^{3}$ Ephedrine has been used in cases refractory to diuretics. ${ }^{4}$ In some patients, the condition resolves spontaneously. ${ }^{5}$

The mechanism of oedema is unclear, but suggested mechanisms include increased osmotic effect secondary to glycogen production, increased capillary permeability and sodium retention. ${ }^{2}$

This case highlights an unusual cause of oedema in patients treated with insulin, and insulin oedema should be considered in patients presenting with oedema, in whom insulin is recently commenced or intensified.

\section{Key learning points}

> Oedema is a possible side effect of initiation or intensification of insulin therapy.

$>$ Insulin oedema is a diagnosis of exclusion.

$>$ Patients with low body mass index or poorly controlled diabetes may be at risk of insulin oedema.

> Insulin oedema may be treated with diuretics and has a good prognosis.

\section{References}

1 Shaper AG. The insulin-oedema syndrome in African diabetic subjects. Trans R Soc Trop Med Hyg 1966;60:519-25.

2 Evans DJ, Pritchard-Jones K, Trotman-Dickenson B. Insulin oedema. Postgrad Med J 1986;62:665-8.

3 Lee P, Kinsella J, Borkman M, Carter J. Bilateral pleural effusions, ascites, and facial and peripheral oedema in a 19-year-old woman 2 weeks following commencement of insulin lispro and detemir an unusual presentation of insulin oedema. Diabetic Medicine 2007;24:1282-5.

4 Hopkins DF, Cotton S], Williams G. Effective treatment of insulininduced edema using ephedrine. Diabetes Care 1993;16;1026-8.

5 Mamoulakis D, Bitsori M, Galanakis E, Raissaki M, Kalmanti M. Insulin-induced oedema in children and adolescents. J Paediatr Child Health 2006;42:655-7.

Address for correspondence: Prof Tahseen A Chowdhury, Department of Diabetes and Metabolism, 7th Floor, John Harrison House, The Royal London Hospital, Whitechapel, London E1 1BB, UK.

Email: tahseen.chowdhury@nhs.net 